\title{
A REFLECTION ON THE EFFECTS OF TRANSPORT COSTS WITHIN THE NEW ECONOMIC GEOGRAPHY
}

\author{
Olga Alonso-Villar
}

\author{
University of Vigo, Vigo, Spain
}

\begin{abstract}
This paper analyzes, in the light of recent contributions of New Economic Geography models, the spatial consequences of transport cost reductions. So far, the role of transport costs have been only partially unveiled; papers focused either on the Dixit-Stiglitz-Iceberg framework or on the alternative framework put forth by Ottaviano et al. (2002), - which departs from the former in preferences and transport modeling. This paper goes a step further, offering a comprehensive view that includes the two approaches, in contexts both of two and of more than two locations. Contrary to other revisions of the literature focused mainly on the centripetal forces included in these models, we emphasize the role of dispersion forces. In a two-location setting, the results seem quite robust against changes in transportation modeling, so that considering either multiplicative transport costs or additive the predictions are identical. However, when allowing for a multilocation setup, the analysis becomes more complex.
\end{abstract}

\section{Introduction}

In the last few years, a great number of works involved in what has been called the New Economic Geography (henceforth, NEG) have analyzed the agglomeration mechanisms of economic activity. Most of these papers use a common setup where individuals love variety in consumption through a CES utility function; manufactures are produced under increasing returns to scale at firm level, in a framework of monopolistic competition à la Dixit-Stiglitz; and transport/trade costs are of an iceberg type - that is, a proportion of the delivered good "melts away" in transit. These costs symbolize the difficulties of trading between locations in a broad sense, so that they may refer to trade barriers or transportation itself. One of the main concerns of this literature has been the impact of economic integration, represented by reductions in transport/trade cost, on industrial agglomeration. However, the predictions of these studiesDo not always coincide. Some papers suggest that reducing transport costs between locations fosters concentration of economic activity; a few of them yield opposite conclusions, while others point out a nonmonotonic relationship between transportation and agglomeration.

The purpose of this paper is to analyze, in the light of recent contributions of NEG models, the spatial consequences of transport cost reductions, showing the key modeling strategies that can help to explain the differences between the outcomes obtained. Some previous overviews concentrated their efforts on the intellectual roots of this literature, showing their strengths and 
weaknesses. ${ }^{1}$ Other works offered a general view of the field, showing the wide range of issues addressed, while emphasizing the mechanisms yielding agglomeration. ${ }^{2}$ The topic of this paper is of a more restrictive nature, as it focuses on a particular issue - the effects of manufacturing transport costs- and so allows us to go deeper in the analysis. So far, the role of transport costs has been only partially unveiled, since papers have focused either on the Dixit-Stiglitz-Iceberg framework or on the alternative framework put forth by Ottaviano et al. (2002), which departs from the former in preferences and transport modeling. This paper goes a step further, offering a comprehensive view that includes the two approaches in contexts both of two and of more than two locations. ${ }^{3}$ This analysis will allow us to highlight how sensitive the results of the NEG models are to the structure of the iceberg function.

As opposed to other revisions of the literature, which have focused mainly on the centripetal forces included in these models, we emphasize the role of dispersion forces. We show that not only can the centrifugal force modeling strategy be crucial in the analysis, but also the number of these forces. This allows us to compare these models from another point of view, so that the logic of functioning can be better understood. We also show that additional assumptions in the modeling approach can reduce the effect of a centrifugal force explicitly included in the analysis, thus making it ineffective.

The study also suggests that in a two-location economy the results seem quite robust against changes in transportation modeling, so that considering either multiplicative transport costs (due to iceberg costs) or additive (when measured instead in terms of a numéraire) the predictions are identical. However, moving from the bidimensional case to a multilocation framework is not as simple as expected. In particular, transportation modeling becomes crucial; this suggests that the iceberg transport structure, recently analyzed by McCann (2005), plays a more important role in a multilocation setup.

This paper is organized as follows. In Section 2, we show the effects of improvements in transportation in a two-location economy with labor mobility. In doing so, we briefly summarize the core-periphery model of Krugman (1991). While the centripetal forces used in his analysis to explain agglomeration are quite common among subsequent papers, different dispersion forces have been considered. We show that the results of improvements in transport costs can strongly depend on the working centrifugal force. In Section 3, we show the results of this literaturestill in the two-location setting - when workers are geographically immobile. Furthermore, the different effects of improvements in transporting final goods and intermediates are analyzed. Section 4 presents the consequences of transport cost reductions in a multilocation economy by distinguishing between domestic and international transportation. Section 5 shows the main conclusions.

\section{A two-location economy with labor mobility}

In his seminal paper, Krugman (1991) assumes an economy with two locations and two sectors (agriculture and manufacturing). Farmers produce a homogenous good, which is freely

${ }^{1}$ See Neary (2001) and Fujita and Krugman (2004), among others.

${ }^{2}$ In this vein, Fujita etal. (2000) offer a detailed description of this literature. See also Puga (2002), Fujita and Thisse (2002), Ottaviano and Thisse (2004), and Fujita and Mori (2005a).

${ }^{3}$ Baldwin et al. (2003) offer a thorough analysis of the two approaches in a two-location setup from a different perspective. 
traded, under constant returns to scale. ${ }^{4}$ Manufactures are, however, produced under increasing returns to scale because of fixed costs in production, where labor is the only input. Each firm produces a different variety by using a common technology, and competes with the others in a monopolistic competitive framework à la Dixit-Stiglitz (1977). Manufactured goods can be transported to the other location at a cost. These transport costs take the convenient iceberg form, so that a part of the good "melts away" in transit. That is, transport costs are incurred in the good being shipped. In this economy, individuals have Cobb-Douglas preferences between the agricultural good and an aggregate of manufactures. This aggregate is actually a CES subutility, which means preference for variety. There are two types of individuals, differing in geographical mobility. Farmers are not allowed to move between locations and are equally dispersed between them, while workers can move in order to look for higher real wages. Individuals obtain their earnings in the location where they live, while they can consume goods from both locations.

In this framework, agglomeration arises from the existence of increasing returns at the firm level, from a strong preference for variety in consumption, and from mobility of the manufacturing labor force. On one hand, increasing returns at firm level force the production of each good to be concentrated in a single location. On the other hand, the CES utility function means that there is preference for variety in consumption. Thus, individuals' real income increases in large agglomerations, as they have access to more goods without transporting them from outside. This encourages more individuals to migrate there (forward linkage). In turn, this increase in the number of consumers creates a greater demand for goods, which makes it feasible to sustain a greater number of firms (backward linkage). ${ }^{5}$ Therefore, agglomeration is the result of interactions between the different economic agents - interactions that occur through the market; that is, externalities are of a pecuniary, not technological, nature.

However, in Krugman (1991) not all factors are mobile, as mentioned above. In fact, farmers cannot move between locations. This rural market works as a centrifugal force that halts agglomeration, since it represents a dispersed and immobile demand toward which firms would also like to turn. We now show the basic behavior of the model by studying the numerical simulations obtained with different transport/trade costs $(t \geq 0)$. These costs represent the difficulties of trading between locations, both those that arise from the problem of distance (information, transport) as well as possible trade barriers if the two locations are in different countries. ${ }^{6}$

\footnotetext{
${ }^{4}$ Davis (1998) shows that when both manufactured goods and agriculture have identical transport costs, the home market effect vanishes. This suggests that the location in the larger country will no longer be preferred by firms unless the relative trade costs of manufactures are high enough. Fujita et al. (2000) maintain that agricultural transport costs work against agglomeration, even though some of the most important results of the core-periphery model remain unchanged when these costs are low enough.

${ }^{5}$ Redding and Venables (2004) provide evidence of the importance of access to markets to determine the factor prices that manufacturing firms can afford to pay. For example, access to the coast raises per capita income by $20 \%$. Radelet and Sachs (1998) also find that access to the sea and distance to major markets affect manufactured export growth.

${ }^{6}$ Glaeser and Kohlhase (2004) show evidence of the decline of transportation costs in the USA throughout the twentieth century. They suggest that transporting goods should no longer be an important matter to explain location. However, Radelet and Sachs (1998) suggest that this is still an important issue for less developed countries. Also, McCann and Shefer (2004) point out that the present increase in the quantity, variety and complexity of information makes spatial transaction costs increase. They also suggest that, in many industries, the complexity of the logistics operations may lead to higher transaction costs in shipping goods over space.
} 
Figure 1. Centrifugal force: demand pull.

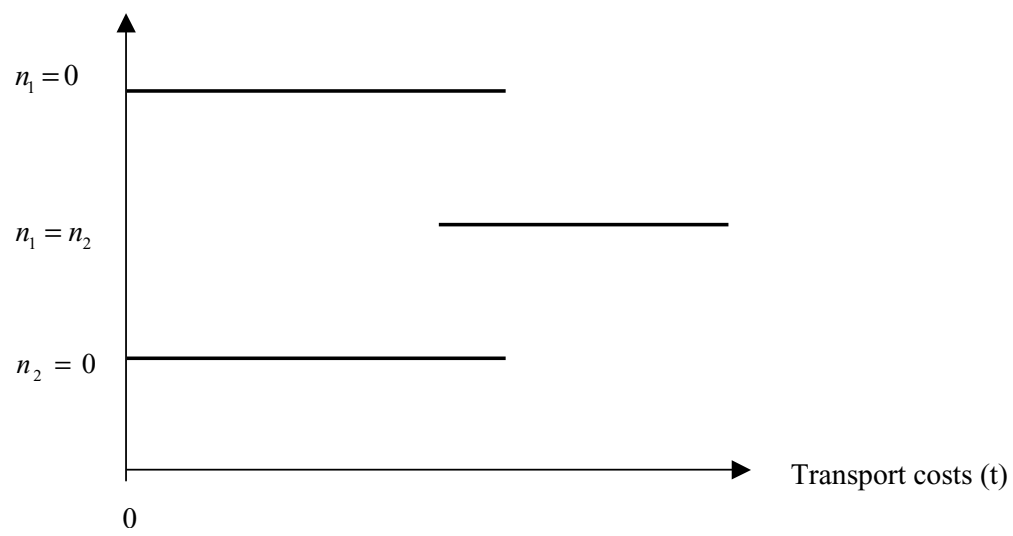

Figure 1 shows the stable equilibria of the economy. Line $n_{1}=n_{2}$ represents a spatial distribution where each location has the same number of firms (and individuals), whereas $n_{1}=$ 0 and $n_{2}=0$ mean full concentration of firms in locations 2 and 1, respectively. We see that, at high values of $t$, an even distribution of the economic activity between both locations emerges as equilibrium. At intermediate transport costs, three stable equilibria arise in the economy: one, where firms are evenly distributed between the two regions, and the other two where firms concentrate in a single location. At low values of $t$, there is full agglomeration, so that depending on whether firms concentrate in region 1 or in region 2, two stable equilibria are possible. These results can be summarized as follows.

Result 2.1 In the core-periphery model proposed by Krugman (1991), the lower the transport costs, the more likely it is to find agglomeration in one location. ${ }^{7}$

The explanation is as follows: if transport costs are low, firms can benefit from concentrating their production in the larger market while delivering the goods to farmers in the other location. However, if transport costs are high, firms are more interested in reaching the dispersed rural market, so that an even distribution of production between both locations emerges.

More recently, Forslid and Ottaviano (2003) develop an analytically solvable version of Krugman (1991), yielding the same results. ${ }^{8}$ To this end, they introduce differences in skill and mobility among workers. In particular, the fixed cost of manufacturing firms involves skilled and mobile workers, whereas the variable cost involves unskilled and immobile labor. This difference with respect to Krugman (1991), where the same mobile labor force was used for both fixed and variable costs, allows for price equalization between locations, and makes the model more tractable.

Ottaviano et al. (2002) (hereafter OTT) present an alternative framework that differs from the standard Dixit-Stiglitz-Iceberg framework, since utility is quasi-linear quadratic rather than

\footnotetext{
${ }^{7}$ Puga (1999) obtains the same results by building a model that includes another centripetal force: input-output linkages.

${ }^{8}$ Robert-Nicoud (2005) proves that both models are isomorphic, since they can be characterized by the same set of equations.
} 
Figure 2. Centrifugal force: urban costs.

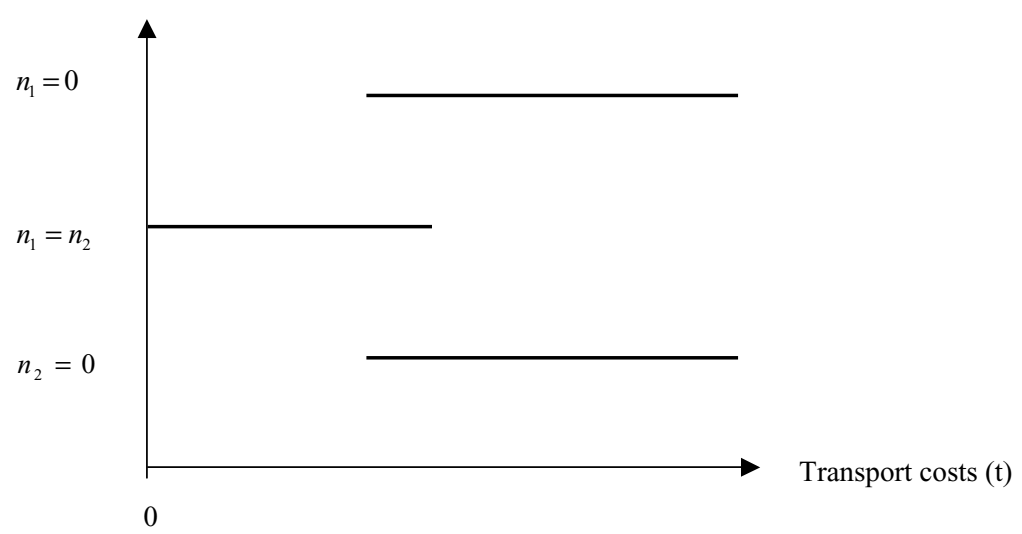

Cobb-Douglas nested-CES, and transport costs are measured in terms of a numéraire instead of the own good. This paper also leads to analytical results mirroring those of Krugman (1991). ${ }^{9}$ In particular, we can write the following result.

Result 2.2 When dispersion is caused by the demand pull, and the economy consists only of two locations, the results of the core-periphery model are quite robust against alternative formulations of preferences and transportation. ${ }^{10}$

\section{I Farmers versus urban costs}

In a regional/international context, to assume the existence of an immobile demand such as that represented by farmers in Krugman (1991) seems reasonable. However, if we focus on an urban context, it would not be realistic to assume that population is immobile. Large cities have other elements that limit their growth: such as high housing prices, commuting costs, or environmental pollution. These factors make smaller-sized cities comparatively more attractive places to live. To assume that dispersion is due to these urban costs and not to the existence of an immobile agricultural sector is not innocuous, since the effects of a gradual decrease on transport costs can be considerably different - as discussed in Alonso-Villar (2001a), who uses congestion costs, and in Murata and Thisse (2005), who explicitly decompose urban costs in housing and commuting.

In Figure 2, we can see that as transport cost decreases, it is more difficult for concentration to emerge as equilibrium. By considering consumption of housing services alone, Helpman

${ }^{9}$ See Ottaviano and Thisse (2004) for a survey of the literature within this alternative framework.

10 Bjorvatn (1999) proposes an alternative approach to NEG models by considering a framework where goods can be produced by means of two technologies: constant returns (informal sector production) and increasing returns to scale (formal sector production); and where mobile and immobile labor exists. In this economy, only two goods are produced and new firms can compete with the existing ones by using a different technology for the same good, rather than using the same technology for a different good, as in models à la Dixit-Stiglitz. As in Krugman (1991), immobile labor is the centrifugal force of the model. However, as opposed to this, reductions in transport costs foster convergence instead of halting it, which suggests that drastic departures from the Dixit-Stiglitz framework may substantially affect the results. 
(1998) also found a similar pattern — even though at intermediate transport costs, the symmetric equilibrium was unstable, while asymmetric configurations emerged as stable equilibria.

Result 2.3 Unlike the model with the immobile rural market, when considering urban costs, improvements in transport systems between cities generate a greater dispersion of economic activity.

When communications between locations are good, individuals can enjoy the advantages of proximity to a large city (in particular, the numerous commodities available), while living in smaller cities where urban costs are lower.

\subsection{Two simultaneous centrifugal forces}

So far, we have analyzed the effects of different centrifugal forces considered separately. Now, we show the predictions of this literature when taking into account two simultaneous centrifugal forces in the modeling. The demand pull is a common dispersion force considered by these papers, while the second force differs among them. Some focus on urban costs (housing and commuting), while others focus on wage differentials between locations.

In this vein, by conducting numerical simulations, Tabuchi (1998) shows that when considering urban costs together with demand pull, dispersion emerges at both low and high transport costs. ${ }^{11}$ At low transport costs, consumers prefer to disperse to enjoy greater consumption of land (and lower commuting costs), while at high transport costs, the demand pull-which arises from immobile farmers who are geographically dispersed - is the force driving the result. More recently, Alonso-Villar (2006) yields analytical results that corroborate previous findings. ${ }^{12}$ It follows then, that when jointly considering both centrifugal forces, the effect of transport costs on the spatial distribution of economic activity is nonmonotonic. These results can be summarized as follows.

Result 2.4 When considering urban costs together with demand pull, dispersion emerges at both low and high transport costs. In other words, when transport costs gradually decrease, production tends first to agglomerate and later to disperse between locations.

The relationship between the distribution of production and transport costs could be as shown in Figure 3, which suggests a combination of Figures 1 and 2, driven by the opposite effects of the two centrifugal forces (demand pull and urban costs). ${ }^{13}$

Result 2.5 The above bell-shaped relationship has also been obtained in frameworks other than that of Dixit-Stiglitz-Iceberg.

As a matter of fact, when using the approach of OTT, which considers alternative assumptions about preferences and transportation costs, several papers yield the same result by

11 Forslid et al. (2002) find evidence of this relation between transport costs and overall concentration of manufacturing activities in Europe by using a CGE-model.

12 Tabuchi (1998) finds analytical results for only two extreme cases: zero and infinite transport costs.

13 This figure shows a gradual change between dispersion and agglomeration, so that asymmetric distributions of production between locations are stable equilibria. However, this change could be more drastic, as will be shown later on, so that only full concentration and the symmetric equilibrium could be stable. 
Figure 3. Two centrifugal forces: urban costs and demand pull.

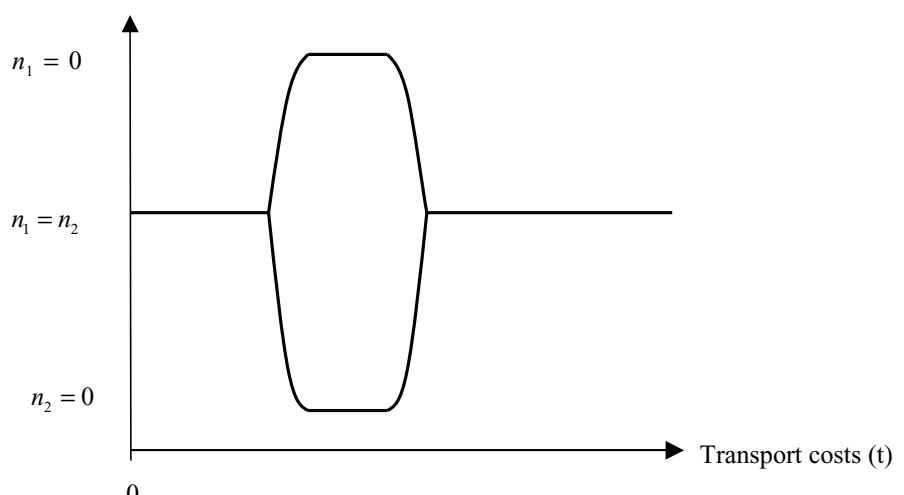

considering an immobile demand (farmers) together with another centrifugal force (Tabuchi and Thisse, 2002; Picard and Zeng, 2005). In this regard, OTT model shows that dispersion of production arises at both high and low transport costs when including urban costs in the analysis. Tabuchi and Thisse (2002) also obtain a bell-shaped relationship by assuming that individuals have heterogeneous tastes with respect to the attributes of regions, since this heterogeneity acts as "a strong dispersion force that dramatically affects the core-periphery structure" (p. 174). Picard and Zeng (2005) reach similar results by using another centrifugal force, salary differentials, which comes into play by incorporating transport costs in the agricultural sector. ${ }^{14}$ They show that when these costs are large, the manufacturing industry tends to disperse because of wages, but when they are low the spatial distribution of manufacturing is again nonmonotonic with respect to reductions in its own transport costs. ${ }^{15}$

\section{A two-location economy with labor immobility}

In the previous section we assumed that the industrial labor force could move between locations looking for higher real wages. This assumption is quite reasonable and realistic if our intention is to study the agglomeration phenomenon in the context of the USA. However, in other contexts this mobility either does not exist or is limited by government. In Europe, for example, this interregional movement cannot be observed, in spite of the fact that regional wage differences are, in some cases, sizeable. In what follows we show the effects of transport cost reductions when this element is taken into account.

14 This model assumes that unskilled and immobile labor is used for both manufacturing and agriculture (where two different varieties are produced, one in each location). Competition for these immobile workers causes wages to increase, especially if the agricultural goods are affected by high trade costs.

15 In a continuous one-dimensional space, Fujita and Mori (2005b) demonstrate that, within the Dixit-StiglitzIceberg framework, the spatial distribution of economic activity also depends on the relative decrease of transport costs for agricultural and manufacturing goods. However, their results seem to differ from those obtained by Picard and Zeng (2005). 
Krugman and Venables (1995), Venables (1996), and Puga (1999) propose introducing new elements into Krugman's approach and exclude the possibility of labor mobility between the two locations. First, they consider the existence of two industries vertically linked through an input-output structure, as well as the agricultural sector, which adds a new centripetal force to the model. Second, given that wage differences between locations are now not reduced by migration, firms might be interested in moving to less industrialized areas where production costs are lower. This brings a second centrifugal force to the model, in addition to the demand pull effect caused by the immobile population of each location. Their results can be summarized as follows.

Result 3.1 When considering the demand pull together with wage differentials between locations in a world with labor immobility, the relationship between agglomeration and transport cost is, once again, bell-shaped. At high transport costs, dispersion is driven by the demand pull effect; while at low transport costs, salary differential is the force bringing redispersion of economic activity. ${ }^{16}$

Puga (1999) goes further and suggests that the salary advantage of the periphery would disappear, however, if workers were geographically mobile. Thus, this centrifugal force would become ineffective if there were labor mobility. This explains why in that case dispersion would not appear as a possible stable equilibrium at low transport costs. In other words, even though in a framework with two centrifugal forces we would expect a nonmonotonic relationship between agglomeration and transportation, there may exist additional assumptions of the model that reduce the effect of one of these forces, making it nonoperative. Our claim is that the assumption about labor mobility is important to explain the location of economic activity, but not in the sense commonly suggested. Labor mobility does not always hinder a bell-shaped relationship from appearing. We have shown that the bell-shaped relationship can be obtained both in a context of labor mobility as well as in a framework where workers cannot move. The key is that depending on the specific centrifugal forces considered in the analysis, some of them may become ineffective because of additional assumptions of the modeling framework. In Puga (1999), for example, production cost advantages tend to dissipate when considering labor mobility, so that dispersion can be caused only by the demand pull effect. Thus, we can obtain only the right side of Figure 3, as in Krugman (1991). However, when centrifugal forces other than salary differentials are considered in the analysis, such as urban costs in Tabuchi (1998), labor mobility does not hinder the symmetric equilibrium from emerging at low transport costs.

\section{I The transport costs of final goods versus intermediates}

Krugman and Venables (1995) and Venables (1996) suggest that regional policies interested in regional convergence should improve transportation highly enough to take advantage of low salaries in less developed regions. However, these papers do not discriminate between transportation that benefits final-product firms and that benefiting intermediates. Alonso-Villar (2005) addresses this issue and suggests that the stable equilibria of the economy could now be

\footnotetext{
16 Alonso-Villar and Chamorro-Rivas (2001) suggest that redispersion could actually involve specialization, rather than full convergence, if the two industries differ in knowledge intensity. Amiti (2005) finds similar patterns by allowing the industries to differ in factor intensities.
} 
Figure 4. The stable equilibria when distinguishing between intermediates and final goods.

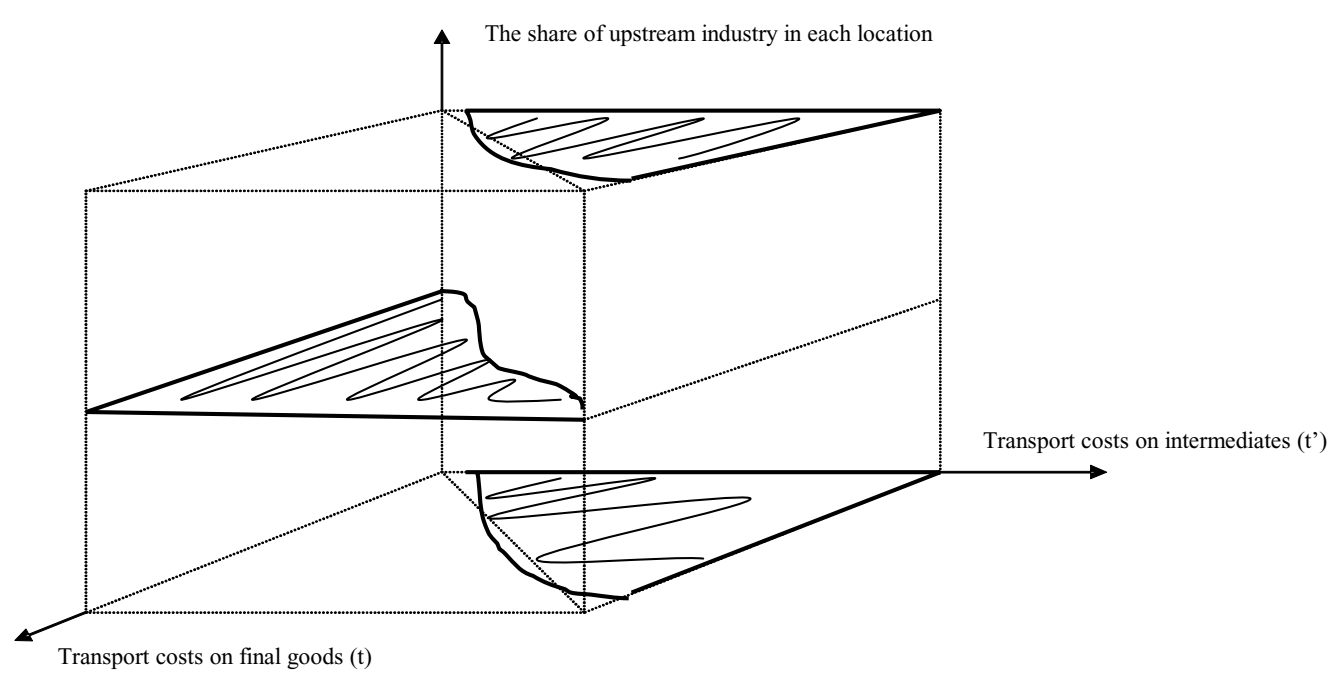

summarized into one 3-D figure with the transport costs of each sector in the two horizontal axes and the share of the industry in the vertical axes (Figure 4).

Upper and lower planes represent concentration of production in regions $2\left(n_{1}=0\right)$ and $1\left(n_{2}=0\right)$, respectively, while the other plane represents an even distribution of production between both locations $\left(n_{1}=n_{2}\right) .{ }^{17}$

To better understand this figure, we can explore three different cases. Figure 5a represents the equilibria of the economy when only the transport costs of final goods $(t)$ varies - which can be obtained from Figure 4 via a cut parallel to the $t$ axis. Figure $5 \mathrm{~b}$ is the corresponding figure when only the transport cost of intermediates $\left(t^{\prime}\right)$ varies - which corresponds to a cut parallel to the $t^{\prime}$ axis - while Figure $5 \mathrm{c}$ represents the case where both transport costs are equal $\left(t=t^{\prime}\right)$. Dark lines represent the stable equilibria of the economy.

It follows then that first, when only $t$ decreases, firms tend to agglomerate, as in Figure 1, since the agglomeration forces become more important than the demand pull caused by the populations of the two locations. Second, when only $t^{\prime}$ diminishes, production tends instead to disperse, as in Figure 2, since salary differentials between locations become more important than proximity between upstream and downstream firms. These results can be summarized as follows.

Result 3.2 When analyzing both trade costs separately, regional convergence is more the consequence of improvements that facilitate trade between upstream and downstream firms than those that facilitate trade between downstream firms and consumers.

It follows then that even in a framework of labor immobility and salary differentials between locations, Krugman's (1991) results can still be obtained by considering the case where only final

\footnotetext{
${ }^{17}$ In order to show the equilibria of the economy in three-dimensional space, the plot has been limited to a cube. In other words, the planes are drawn only until a certain value of $t$ and $t^{\prime}$.
} 
Figure 5a. The stable equilibria when $t$ varies and $t^{\prime}$ is fixed.

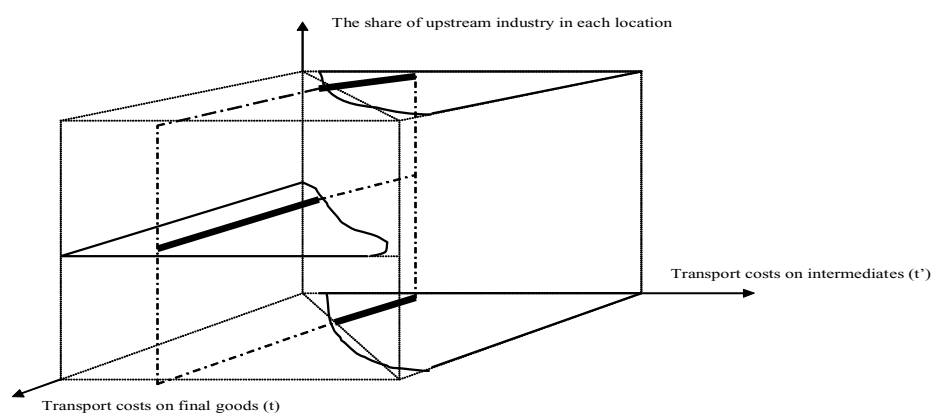

Figure $5 b$. The stable equilibria when $t^{\prime}$ varies and $t$ is fixed.

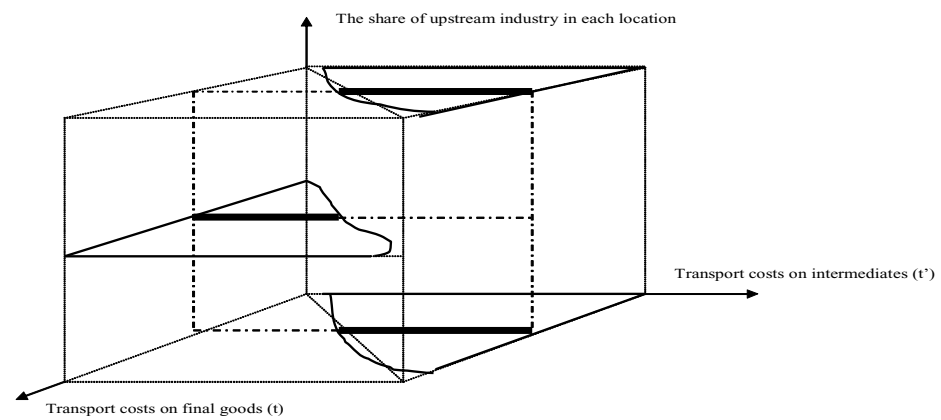

Figure 5c. The stable equilibria when both transport costs are equal.

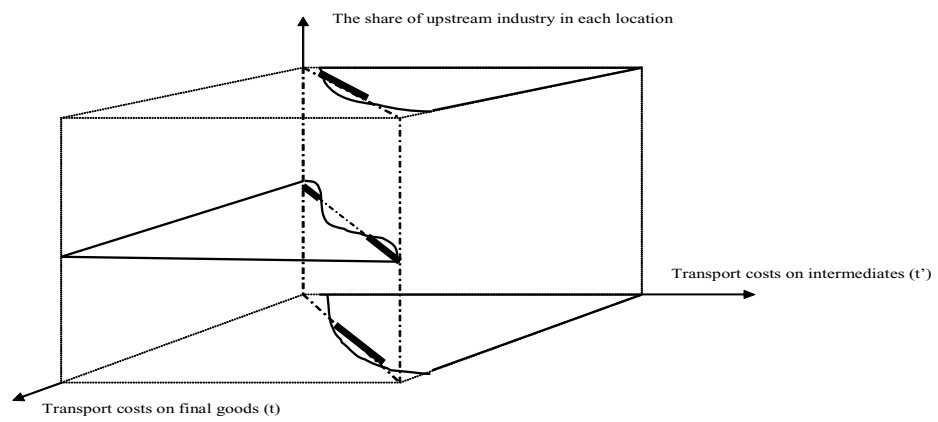

goods experience a reduction in transport costs. Thus, Krugman's (1991) results are not only the consequence of considering labor mobility between locations, as Puga (1999) suggests, but also the consequence of considering only the transport costs of final goods. As Alonso-Villar (2005) shows, salary differential does not play an important role when intermediates are expensive to transport and, therefore the relationship between agglomeration and transport costs would be analogous to that obtained by Krugman (1991). Consequently, it seems that different elements can reduce the dispersion effect caused by wage differentials: labor mobility and high transport costs on intermediates. 
When considering that both transport costs are equal and decreasing, as in Venables (1996), we now observe a more drastic change from dispersion to concentration, and vice versa, than in Figure 3, although the main pattern still remains. ${ }^{18}$ Therefore, the nonmonotonic relationship between agglomeration and transport costs described in Venables (1996) could be the consequence of two transport costs having opposite effects on the spatial distribution of production.

\section{A multilocation economy}

Papers presented in previous sections assumed that the economy consisted of two locations, so that transport improvements affected communications between them. Depending on whether these locations were considered as cities, regions, or countries, transports' improvements could favor, respectively, intrametropolitan trade, regional trade, or international trade-but only one of them. However, there are other studies that distinguish between domestic transportation, that is, that which connects cities or regions in a country, and international, which connects different countries. In what follows, we present the predictions of these models, which assume that labor is mobile at the national level but not at the international one.

\section{I Farmers versus urban costs}

Paluzie (2001) analyzes the effects of reducing international transport costs on domestic agglomeration in a framework with three locations, two in the same country and the other representing the rest of the world. This paper is closely connected to Krugman (1991), so that farmers are again the centrifugal force halting the concentration of economic activity. Her results suggest that improvements in international transport costs facilitate the concentration of economic activity. In a similar framework, Monfort and Nicolini (2000) also extend Krugman (1991) by considering an economy with two countries and two regions in each of them. Their simulations suggest that the effects of reducing interregional transport costs are similar to those of international transport costs, fostering also the concentration of production.

Inspired by the case of Mexico, Krugman and Livas Elizondo (1996) address this topic by assuming that dispersion is no longer due to immobile farmers, but to the high costs of commuting and land prices in large cities. They suggest that agglomeration can be fostered by manufacturers mainly serving the domestic market, so that when international trade costs decrease the agglomeration process becomes weaker. In other words, as opposed to Paluzie (2001) and Monfort and Nicolini (2000), they find that reductions in international transport costs foster the dispersion of economic activity (since dispersion is due to urban costs rather than to immobile demand).

In line with conclusions shown in the previous section, centrifugal force modeling also appears as a relevant factor to explain the effects of reductions in transport costs in a multilocation setup, as summarized below.

Result 4.1 Within the Dixit-Stiglitz-Iceberg framework, the effect of international/domestic transport cost reductions in a three-location economy is analogous to that found in a two-location

\footnotetext{
18 Actually, Venables (1996) shows only the equilibria of the downstream industry. Here, that model has been simulated for the intermediates sector. The only difference between both sectors is that the change from concentration to dispersion (or vice versa) is smoother in the downstream case.
} 
setup. Depending on which centrifugal force is included in the model, that is, farmers or housing/commuting, reductions in transport costs lead to different spatial patterns.

\subsection{Other immobile demands}

In Krugman (1991), farmers represent an immobile demand toward which firms may be interested in moving when transport costs are low enough. He also shows that the larger this immobile demand, the larger the dispersion effect. These farmers produce a homogenous agricultural good, which constitutes a constant expenditure share of individuals' income (utility is of a Cobb-Douglas type between the agricultural good and an aggregate of manufacturing goods). This agricultural good is costless tradeable, so that individuals demand the same amount, irrespective of its location. All this means that when a firm moves closer to farmers, the good it produces does not directly compete with the agricultural good produced there. However, the effects of proximity can be different when competition between similar goods comes into play, as discussed below.

Alonso-Villar (2001b) considers a long and narrow economy with four locations and three countries. Populations in the foreign countries are assumed to be concentrated in a single city. However, the domestic country, located between the other two, has two possible locations, between which individuals can move without restriction. In this paper, the only immobile demand is that represented by the populations of the two foreign markets, who produce manufactured goods with which firms in the domestic country compete. As opposed to Krugman (1991), she finds that when this immobile demand is very large, production in the domestic country tends to agglomerate in a single city, since any deviating firm would have to compete with a large number of foreign firms and would lose part of its national market. This suggests the following result.

Result 4.2 Within the Dixit-Stiglitz-Iceberg framework, the effect of an immobile demand, on the concentration of production, is not always the same. The fact that the potential market does or does not produce other varieties with which to compete appears as a crucial factor.

\subsection{Transport modeling}

More recently, Mansori (2003) has brought a new element to the debate. He extends Krugman and Livas Elizondo (1996) by allowing increasing returns to scale in transportation. This means that the same centrifugal forces (commuting costs and housing) apply. As in Krugman and Livas Elizondo (1996), he finds that as domestic transport costs decrease, dispersion equilibrium becomes more likely - even though the presence of increasing returns mitigates this effect. ${ }^{19}$ This suggests that this change in the domestic transport modeling does not affect the inner distribution pattern. However, as opposed to Krugman and Livas Elizondo (1996), he also finds that when there are increasing returns to scale in transportation, reductions in international transport costs foster agglomeration, since international trade becomes more important and concentration in a single city facilitates transportation. Therefore, when considering the possibility of increasing returns in the transportation sector the results are significantly affected. These results can be summarized as follows.

\footnotetext{
${ }^{19}$ In particular, he finds that the range of domestic transport costs that allows dispersion to emerge as an equilibrium is wider with constant returns than with increasing returns on transportation.
} 
Result 4.3 Within the Dixit-Stiglitz-Iceberg framework, the impact of decreasing international transport costs in a multilocation economy depends on transportation returns.

Result 4.4 However, the effect of domestic transport cost reductions does not seem to depend on these returns, but on the centrifugal force assumed in the model.

Result 4.5 Moreover, the effects of reducing international trade costs are not necessarily the same for reducing domestic trade costs.

In this vein, Behrens (2004) goes further and develops a three-region model based on OTT model to analyze the relative effect of domestic and international trade costs. As previously mentioned, this framework differs from the usual Dixit-Stiglitz-Iceberg one in preferences and transport costs. He shows that the relative level of international to interregional trade costs is important to explain the spatial distribution of production. In particular, he finds that improvements in international trade costs in developing countries (with high domestic trade costs and no interregional trade) may foster regional divergence. However, in the context of developed countries (characterized by low domestic trade costs and large volumes of interregional trade), reductions in international trade costs instead favor convergence. In this latter case, he also shows that reductions in interregional trade costs have the opposite result, fostering agglomeration. These results can be written as follows.

Result 4.6 Within the OTT framework, the impact of decreasing international transport costs in a multilocation economy depends on the level of domestic transport costs.

Result 4.7 The effect of domestic transport cost reductions seems to depend only on the type of centrifugal force assumed in the model.

Result 4.8 Moreover, once again the effects of reducing international trade costs are not necessarily the same for reducing domestic trade costs.

It is not surprising that domestic trade costs have the same effect as in Krugman (1991), since dispersion force is due to demand pull. What is more striking is that the effect of international trade costs does depend on domestic trade costs. To explain this, Behrens (2004) points to the fact that this alternative framework allows the modification of the share of interregional trade costs in delivered prices when international trade costs decrease, while this does not happen in the Dixit-Stiglitz-Iceberg setting.

We can therefore conclude that the effects of reducing international transport costs in a multilocation economy strongly depend on how trade costs are modeled. In fact, when transport costs are not of an iceberg type, the results are significantly affected. In this vein, Ago et al. (2006) suggest that differences between the Krugman and OTT models in a three-location setup stem "from the difference between the degrees of price competition. Firms are involved in fiercer competition with price discrimination under the linear transport costs with the quadratic utility, whereas the opposite is true under the iceberg transport costs with the CES utility."

\section{Concluding remarks}

Among the elements that favor the concentration of economic activity, the NEG literature emphasizes those derived from market interactions: preference for variety in consumption, proximity to consumers, vertical linkages, and returns to scale at firm level. Working in the opposite direction, different centrifugal forces have been considered: congestion costs, commuting and 
housing prices for individuals within a city, taste heterogeneity in labor mobility, the pull of dispersed rural markets, and wage differences between locations.

We have shown that both within the Dixit-Stiglitz-Iceberg framework and within that proposed by Ottaviano et al. (2002), the effects of reducing the manufacturing transport costs in a two-location economy strongly depend on the centrifugal forces considered in the analysis. Moreover, when considering the same centrifugal forces, both approaches yield the same results. Therefore, the results of the NEG literature in a bidimensional setup are quite robust against changes in transportation (and also in preferences) modeling, so that in considering either multiplicative or additive costs the predictions are identical. In this vein, when dispersion is caused only by the demand pull, we find an even distribution of production at high transport costs and full agglomeration at low costs (Krugman, 1991; Forslid and Ottaviano, 2003; Ottaviano etal., 2002). However, when considering alternative centrifugal forces, such as urban costs, the pattern is the opposite (Helpman, 1998; Alonso-Villar, 2001a; Murata and Thisse, 2005). When jointly considering the demand pull with additional dispersion forces (urban costs, taste heterogeneity in labor mobility, or wage differentials) the relationship between agglomeration and transportation is no longer monotonic (due to the opposite roles of the two centrifugal forces), so that symmetric equilibrium is reached at both high and low transport costs (Tabuchi, 1998; Ottaviano et al., 2002; Tabuchi and Thisse, 2002; Picard and Zeng, 2005; Alonso-Villar, 2006).

This bell-shaped relationship can be obtained not only when considering labor mobility, as is assumed in all the aforementioned papers, but also in a framework of labor immobility (Venables, 1996; Puga, 1999). It follows then that both labor mobility and immobility are compatible with the above nonmonotonic relationship. The key is the kind of centrifugal force that is considered in the analysis. However, it should be noted that a given centrifugal force can become ineffective because of additional modeling strategies, so that only one part of the bell appears. In this vein, Puga (1999) shows that the redispersion effect-found at low transport costs due to salary differentials - vanishes when allowing labor mobility. Alonso-Villar (2005) points out that this centrifugal force also becomes ineffective if intermediate goods are affected by high transport costs - so that even if consumption goods experience very low transport costs, a symmetric equilibrium cannot be reached. It follows then that different elements can reduce the dispersion effect caused by wage differentials: labor mobility and high transport costs on intermediates. However, when considering centrifugal forces other than salary advantages, such as urban costs, labor mobility does not hinder the redispersion effect.

It should be noted that most NEG literature emphasizes the centripetal forces considered in these models to explain agglomeration, while centrifugal forces appear as necessary but secondary elements in the modeling. All the above suggests that the centrifugal force modeling strategy should receive more attention, as it can help in a better understanding of the economic logic of these models and, therefore, the outcomes obtained.

We have also shown that the results are more sensitive to preferences and transport modeling strategies in a multilocation economy than in the bidimensional case. In this regard, even within the Dixit-Stiglitz-Iceberg framework, the effects of international transport costs drastically differ depending on whether there are increasing returns in transportation, while increasing returns in domestic transportation do not alter the conclusions reached above in the two-location setup (Mansori, 2003). When departing from the standard approach, so that transport costs are not of the frictional kind and preferences are not Cobb-Douglas nested CES but quasi-linear quadratic, interdependence between domestic and international transport costs arises, so that the analysis 
becomes more complex. In this regard, Behrens (2004) and Ago et al. (2006) point to differences in the degree of price competition among firms between both approaches.

Apart from distinguishing between domestic and international transport costs, the multilocation setup also offers us the possibility of analyzing whether different immobile demands may play different roles. In this regard, by building a model with four locations, Alonso-Villar (2001b) shows that the effect of rural markets (such as that represented by farmers in Krugman, 1991 ) is different from that of industrial markets. While the former works as a dispersion force, the latter has the opposite effect. Depending on whether the potential market produces an agricultural good or manufactures with which firms have to compete, the interest of companies in reaching these markets may be considerably different.

All the above suggest that some of the conclusions reached in a two-location economy do not hold true in a multilocation setting, since the latter brings the possibility of new interactions which do not show up in a simpler framework.

The author thanks the referees for their comments. Financial support from the Ministerio de Educación y Ciencia (grant SEJ2005-07637-C02-01/ECON), from the Xunta de Galicia (PGIDIT06PXIC300184PN) and from FEDER is gratefully acknowledged.

Final version received October 2006.

Send correspondence to Olga Alonso-Villar: ovillar@uvigo.es

\section{References}

Alonso-Villar, O. 2001a. Metropolitan Areas and Public Infrastructure. Investigaciones Económicas XXV(1), 139-169.

Alonso-Villar, O. 2001b. Large Metropolises in the Third World: An Explanation. Urban Studies 38(8), $1359-1371$.

Alonso-Villar, O. 2005. The Effects of Transport Costs Revisited. Journal of Economic Geography, 5, 589-604.

Alonso-Villar, O. 2006. A Model of Economic Geography with Demand Pull and Congestion Costs. ECINEQ Working Paper Series 56.

Alonso-Villar, O. and Chamorro-Rivas, J.M. 2001. How Do Producer Services Affect the Location of Manufacturing Firms? The Role of Information Accessibility. Environment and Planning A 33(9), $1621-1642$.

Ago, T., Isono, I. and Tabuchi, T. 2006. Locational Disadvantage of the Hub. Annals of Regional Science 40(4), 819-848.

Amiti, M. 2005. Location of Vertically Linked Industries: Agglomeration Versus Comparative Advantage. European Economic Review 49(4), 809-832.

Baldwin, R., Forslid, R., Martin, P., Ottaviano, G. and Robert-Nicoud, F. 2003. Economic Geography \& Public Policy. New Jersey: Princeton University Press.

Behrens, K. 2004. International Integration and Regional Inequalities: How Important is National Infrastructure? CORE Discussion Paper 2004/66.

Bjorvatn, K. 1999. Third World Regional Integration. European Economic Review 43, 47-64.

Davis, D. 1998. The Home Market, Trade and Industrial Structure. American Economic Review 88(5), $1264-1276$.

Dixit, A.K. and Stiglitz, J.E. 1977. Monopolistic Competition and Optimum Product Diversit. American Economic Review 67(3), 297-308. 
Forslid, R., Haaland, J. and Midelfart Knarvik, K. 2002. A U-shaped Europe? A Simulation Study of Industrial Location. Journal of International Economics 57, 273-297.

Forslid, R. and Ottaviano, G. 2003. An Analytically Solvable Core-periphery Model. Journal of Economic Geography 3, 229-240.

Fujita, M. and Krugman, P. 2004. The New Economic Geography: Past, Present and the Future. Papers in Regional Science 83, 139-164.

Fujita, M., Krugman, P. and Venables, A. 2000. The Spatial Economy: Cities, Regions, and International Trade, 2nd printing. Massachusetts: The MIT Press.

Fujita, M. and Mori, T. 2005a. Frontiers of the New Economic Geography. Papers in Regional Science 84(2), 377-405.

Fujita, M. and Mori, T. 2005b. Transport Development and the Evolution of Economic Geography. Portuguese Economic Journal 4, 129-156.

Fujita, M. and Thisse, J.F. 2002. Economics of Agglomeration. Cities, Industrial Location, and Regional Growth. Cambridge University Press.

Glaeser, E. and Kohlhase, J. 2004. Cities, Regions and the Decline of Transport Costs. Papers in Regional Science 83, 197-228.

Helpman, E. 1998. The Size of Regions. In Pines, Sadka and Zilcha (eds), Topics in Public Economics. Cambridge University Press.

Krugman, P. 1991. Increasing Returns and Economic Geography. Journal of Political Economy 99, 483499.

Krugman, P. and Livas Elizondo, R. 1996. Trade Policy and the Third World Metropolis. Journal of Development Economics 49, 137-150.

Krugman, P. and Venables, A. 1995. Globalization and the Inequality of Nations. Quarterly Journal of Economics, 110, 857-880.

Mansori, K. 2003. The Geographic Effects of Trade Liberalization with Increasing Returns in Transportation. Journal of Regional Science 43(2), 249-268.

McCann, P. 2005. Transport Costs and New Economic Geography. Journal of Economic Geography 5, 305-318.

McCann, P. and Shefer, D. 2004. Location, Agglomeration and Infrastructure. Papers in Regional Science 83, 177-196.

Monfort, P. and Nicolini, R. 2000. Regional Convergence and International Integration. Journal of Urban Economics 48, 286-306.

Murata, Y. and Thisse, J.-F. 2005. A Simple Model of Economic Geography à la Helpman-Tabuchi. Journal of Urban Economics 58, 137-155.

Neary, P. 2001. Of Hype and Hyperbolas: Introducing the New Economic Geography. Journal of Economic Literature 39(2), 536-561.

Ottaviano, G., Tabuchi, T. and Thisse, J.-F. 2002. Agglomeration and Trade Revisited. International Economic Review 43, 409-436.

Ottaviano, G. and Thisse, J.-F. 2004. Agglomeration and Economic Geography. In Henderson and Thisse (eds), Handbook of Urban and Regional Economics. Amsterdam, the Netherlands: Elsevier.

Paluzie, E. 2001. Trade Policy and Regional Inequalities. Papers in Regional Science 80, 67-85.

Picard, P. and Zeng, D.Z. 2005. Agricultural Sector and Industrial Agglomeration. Journal of Development Economics 77, 75-106.

Puga, D. 1999. The Rise and Fall of Regional Inequalities. European Economic Review 43(2), 303-334.

Puga, D. 2002. European Regional Policies in Light of Recent Location Theories. Journal of Economic Geography 2(4), 372-406.

Radelet, S. and Sachs, J. 1998. Shipping Costs, Manufactured Exports, and Economic Growth. Paper presented at the American Economic Association Meetings, Chicago.

Redding, S. and Venables, A. 2004. Economic Geography and International Inequality. Journal of International Economics 62, 53-82.

Robert-Nicoud, F. 2005. The Structure of Simple 'New Economic Geography' Models (or, On Identical Twins). Journal of Economic Geography 5, 201-234. 
Tabuchi, T. 1998. Urban Agglomeration and Dispersion: A Synthesis of Alonso and Krugman. Journal of Urban Economics 44, 333-351.

Tabuchi, T. and Thisse, J.-F. 2002. Taste Heterogeneity, Labor Mobility and Economic Geography. Journal of Development Economics 69, 155-177.

Venables, A.J. 1996. Equilibrium Locations of Vertically Linked Industries. International Economic Review $37,341-359$. 